\title{
Vitamin E Analogue Protects Red Blood Cells against Storage-Induced Oxidative Damage
}

\author{
Adam Antosik Kamila Czubak Natalia Cichon Pawel Nowak Halina Zbikowska \\ Department of General Biochemistry, University of Lodz, Lodz, Poland
}

\section{Keywords}

Red blood cell · Storage $\cdot$ Trolox $\cdot$ Mannitol . Oxidative damage

\section{Summary}

Background: To investigate i) the effects of Trolox ${ }^{\circledR}$ or mannitol, which represent two different classes of antioxidants, on oxidative changes generated in manually isolated red blood cells (RBCs) from citrate-phosphatedextrose (CPD) preserved whole blood, followed by up to 20 days refrigerated storage, and ii) whether Trolox supplemented to the blood bank-manufactured salineadenine-glucose-mannitol (SAGM) preserved RBC units would offer better storage conditions compared with SAGM alone. Methods: The percentage of hemolysis and extracellular activity of lactate dehydrogenase (LDH) was measured to assess RBC membrane integrity. Lipid peroxidation, reduced glutathione (GSH) levels and total antioxidant capacity (TAC) were quantified by thiobarbituric acid-reactive substances (TBARS), Ellman's reagent and 2, 2'-azinobis-(3-ethylbenzothiazoline-6-sulfonate) $\left(\mathrm{ABTS}^{+}{ }^{+}\right.$) based assay, respectively. Results: Trolox was little more effective than mannitol in protecting against progressive RBC hemolysis. Trolox $(0.125-3.125 \mathrm{mmol} / \mathrm{l})$ inhibited storage-induced leakage of LDH, lipid peroxidation, and to a lesser extent GSH depletion. Mannitol at these concentrations neither inhibited TBARS formation nor prevented GSH depletion. RBC units stored in SAGM-Trolox had significantly lower hemolysis, LDH leakage, and lipid peroxidation level compared to RBCs stored in SAGM. Conclusion: There is evidence of the beneficial effects of supplementing RBC-additive solutions with membrane-interacting antioxidants such as vitamin $E$ analogues.

(c) 2018 S. Karger GmbH, Freiburg

\section{Introduction}

The currently licensed additive solutions (AS) could extend the shelf-life of red blood cells (RBCs), allowing up to 42 days of refrigerated storage [1-3]. During storage, RBCs undergo complex and progressive metabolic, biochemical, and physiological changes with the concomitant release of potentially hazardous bioactive products that are known as RBC storage lesion. The accumulating metabolites, altered proteins, and microparticles can be released into the supernatant [4]. Damage affecting the membrane and cytoskeleton results in altered deformability and shape and compromises RBC integrity [5]. The clinical relevance of the storage lesion and its effects on patient outcomes are intensively discussed at present [6-10]. Additionally, some studies demonstrated that transfusion of older stored RBC units more frequently is accompanied by poorer outcomes when compared to that of fresher RBCs $[11,12]$. In order to address these concerns, there is renewed interest to find ways to ameliorate the deleterious effects of storage, thereby improving the quality, efficacy, and safety of RBC components for transfusion recipients [3].

Oxidative damage to the membrane lipids and proteins contributes to RBC injury during hypothermic storage $[13,14]$. Storage of $\mathrm{RBCs}$ can result in lipid peroxidation, membrane integrity impairment, which is manifested by increased activity of extracellular lactate dehydrogenase $(\mathrm{LDH})$, increased hemolysis, and leakage of potassium ions $[2,7,15,16]$. Moreover, a decline of endogenous antioxidant systems, including reduced glutathione (GSH) concentration and glutathione peroxidase activity, has also been demonstrated [13]. One approach to improve the RBC quality during storage is to reduce oxidative stress by antioxidant addition. Nevertheless, there is limited data if RBCs can be protected against storage lesions by antioxidants. Using the model blood-saving experimental system (RBCs manually isolated from whole blood (WB) and stored in polystyrene tubes), we have recently shown a moderate protection of RBCs against $\gamma$-irradiation- and storage-induced

\section{KARGER}

() 2018 S. Karger GmbH, Freiburg

Fax +497614520714 
oxidative damage when adding quercetin, a flavonoid with antioxidant properties, to the storage medium [17].

The majority of the currently licensed RBC AS, including saline-adenine-glucose-mannitol (SAGM), contain mannitol which helps to protect the RBC membrane and reduce hemolysis $[3,18]$. Mannitol has been shown to act as a hydroxyl radical $(\cdot \mathrm{OH})$ scavenger in various systems $[19,20]$ but it has also been found to promote leakage of potassium both from irradiated (30 Gy) and non-irradiated RBCs stored for 7 days [21]. Trolox ${ }^{\circledR}$, a phenolic antioxidant, is a water soluble vitamin $\mathrm{E}$ analogue which has a carboxylic group in position 2 instead of a phytyl chain. It can penetrate membranes and protect mammalian cells against cellular damage induced by oxidants $[22,23]$. Trolox was shown to be effective in protecting RBCs during photodynamic treatment $[24,25]$.

The aim of the present study was to investigate the effects of Trolox (0.001-3.125 mmol/l) on the oxidative changes generated in RBCs, manually isolated from citrate-phosphate-dextrose (CPD) preserved WB followed by up to 20 days of refrigerated storage. The variables measured included percentage of hemolysis, activity of extracellular LDH, concentrations of the thiobarbituric acid-reactive substances (TBARS) and GSH, and total antioxidant capacity (TAC). was used in the study to compare The antioxidant/protective efficacy of Trolox was compared with that of mannitol. Moreover, we investigated whether Trolox supplemented to the blood bank-manufactured SAGM-preserved RBCs, stored in standard plastic bags, would offer better storage conditions compared with SAGM alone.

\section{Material and Methods}

\section{Material}

WB from 13 donors as well as SAGM-preserved RBC transfusion units derived from 3 donors were obtained from the Regional Center for Transfusion Medicine in Lodz (Poland). Briefly, $450 \pm 10 \% \mathrm{ml}$ of WB was collected from healthy volunteer donors in blood bags (CompoFlex ${ }^{\circledR}$; Fresenius Kabi AG, Bad Homburg, Germany) containing CPD anticoagulant preservative solution. RBC units (leukocytes < $10^{6} /$ unit) were prepared according to standard procedures and suspended in $100 \mathrm{ml}$ of SAGM storage solution. Each of the SAGM-preserved RBC units was split into four equal aliquots with a volume of approximately $65 \mathrm{ml}$, in JMS transfer bags (JMS Singapore Pte Ltd, Singapore) providing three sets of RBC packs for the study. These RBC 'pediatric' units were shipped to our institution on day +2 after collection. The present study was approved by the local Ethics Committee (no KBBN-UŁ/I/4/2011).

2,2'-azinobis-(3-ethylbenzothiazoline-6-sulfonic acid) (ABTS), 5,5'-dithiobis-(2-nitrobenzoic acid) (DTNB), 6-hydroxy-2,5,7,8-tetramethylchromane2-carboxylic acid (Trolox), mannitol, nicotinamide adenine dinucleotide (NADH), potassium persulfate, sodium pyruvate, and thiobarbituric acid (TBA) were purchased from Sigma-Aldrich Chemical Co. (Warsaw, Poland). Drabkin's reagent was purchased from Aqua-Med (Lodz, Poland). Other chemicals, all of the analytical grade, were obtained from Chempur (Piekary Slaskie, Poland).

\section{Preparation and Storage of RBCs, the Design of the Study}

In this study, RBCs prepared by two different procedures were used. The preliminary study, aimed to establish the optimal Trolox concentration/, was conducted using RBC suspensions prepared from the CPD-preserved WB.
Briefly, WB was centrifuged $(2,800 \times g$ for $10 \mathrm{~min})$, plasma was removed, and then the top layer of packed red cells containing white blood cells and platelets was removed by aspiration and discarded. A RBC concentrate with approximately $70 \%$ hematocrit $(\mathrm{Ht})$ was prepared by addition of autologous plasma to the remaining packed cells. The mean $( \pm$ SD) Ht and WBC count in these 'manually' prepared RBCs were $68.4 \pm 3.1 \%$ and $3.5 \pm 1.9 \mathrm{WBC} / \mathrm{ml}$, respectively. The WBC count was assessed using the hemocytometer (FEIN-OPTIC, Bad Blankenburg, Germany). These CPD-preserved RBCs also served to study the effects of mannitol (at the selected optimal concentrations) on the storage lesion. For this preliminary and comparable study, the RBC concentrate was divided into aliquots (volume of $10 \mathrm{ml}$ each). One aliquot was used as a control (not containing the antioxidant), the others were stored either in the presence of Trolox (at concentrations of $1,5,25,125,625$ and $3,125 \mu \mathrm{mol} / \mathrm{l}$ ) or in the presence of mannitol (at concentrations of 125, 625 and 3,125 $\mu \mathrm{mol} / \mathrm{l}$ ). Polystyrene tubes with $\mathrm{RBC}$ concentrates were stored at $4 \pm 2{ }^{\circ} \mathrm{C}$ for up to 20 days. Samples were collected at day 1,10 , and 20.

The second part of the study was conducted using the commercially prepared SAGM-preserved, leukocyte-depleted 'pediatric' RBC units. The mean ( \pm $\mathrm{SD}) \mathrm{Ht}$ and $\mathrm{WBC}$ count in these RBC units were $67.6 \pm 2.5 \%$ and $<4 \mathrm{WBC} / \mu \mathrm{l}$, respectively. Trolox stock solution, filtered through a membrane filter $(0.2 \mu \mathrm{m}$; Merck Millipore, Darmstadt, Germany), was added to the RBC units through the sterile coupler. SAGM-preserved RBCs, supplemented or not with Trolox, were stored at $4 \pm 2{ }^{\circ} \mathrm{C}$ for up to 42 days. Samples were collected aseptically at day $1,10,20$, and 30 (morphological changes were additionally determined at day 42 ) after gentle mixing by inversion.

\section{Hemolysis Measurement}

The rate of hemolysis was calculated based on the measurement of hemoglobin $(\mathrm{Hb})$ released from the cells, relatively to the total amount of $\mathrm{Hb}$ in the $\mathrm{RBC}$ suspension. Free $\mathrm{Hb}$ concentration was determined by cyanohemoglobin method using Drabkin's reagent. The percentage of hemolysis was calculated as described in [26] using the following formula: \% hemolysis $=($ the measured free $\mathrm{Hb}$ concentration $(\mathrm{g} / \mathrm{dl}) \times$ supernatant volume $(\mathrm{dl}) /$ total $\mathrm{Hb}(\mathrm{g})) \times 100$. Supernatant volume was calculated from $\mathrm{Ht}$.

\section{LDH Activity Measurement}

Extracellular LDH activity was measured by following a decrease in absorbance at a wavelength of $\lambda=340 \mathrm{~nm}$ (Spectrophotometer Ultraviolet/Visible (UV/Vis) Helios alpha Unicam, Thermo Fisher Scientific, Waltham, MA, USA) resulting from the NADH oxidation [27].

\section{Lipid Peroxidation and Glutathione Measurement}

Lipid peroxidation was quantified by measuring the concentration of the thiobarbituric acid-reactive substances [28]. Briefly, equal volumes of the RBC suspension $(\mathrm{Ht}=4 \%), 15 \%(\mathrm{~m} / \mathrm{v})$ trichloroacetic acid containing $0.25 \mathrm{~mol} / \mathrm{l}$ $\mathrm{HCl}$, and $0.375 \%(\mathrm{~m} / \mathrm{v})$ TBA (thiobarbituric acid) containing $0.25 \mathrm{~mol} / \mathrm{l} \mathrm{HCl}$ were mixed, incubated at $95{ }^{\circ} \mathrm{C}$ for $10 \mathrm{~min}$, and cooled. The sample was centrifuged at $6,000 \times g$ for $20 \mathrm{~min}$, and absorbance was measured at $535 \mathrm{~nm}$ (Spectrophotometer UV/Vis Helios alpha Unicam). Glutathione content was measured spectrophotometrically with Ellman's reagent. The TBARS and GSH concentrations were calculated using the molar extinction coefficients $(\varepsilon=156,000$ and $13,6001 / \mathrm{mol} / \mathrm{cm}$, respectively).

\section{TAC Measurement}

TAC was estimated by the method of Erel [29]. Briefly, $200 \mu \mathrm{l}$ of $0.4 \mathrm{~mol} / \mathrm{l}$ acetate buffer, $\mathrm{pH} 5.8$, was mixed with $5 \mu \mathrm{l}$ of the RBC supernatant, and the first absorbance was taken at $414 \mathrm{~nm}$ (sample blank, $\mathrm{A}_{0}$ ) (SPECTROstarNano, BMG LABTECH, Ortenberg, Germany). Alternatively, $205 \mu \mathrm{l}$ of the acetate buffer was taken as a blank (to evaluate a spontaneous ABTS.+ discoloration rate). Then, $20 \mu \mathrm{l}$ of the $10 \mathrm{mmol} / 1 \mathrm{ABTS}^{+}$stock solution was added to each well and the last absorbance at $414 \mathrm{~nm}$ (A) was taken at the end of the incubation period ( $5 \mathrm{~min}$ after the mixing). $\mathrm{A}-\mathrm{A}_{0}$ was calculated; the reaction rate was calibrated with Trolox, which is widely used as a traditional standard for TAC measurement assays, and the assay results were expressed in mmol Trolox equivalent/l. 


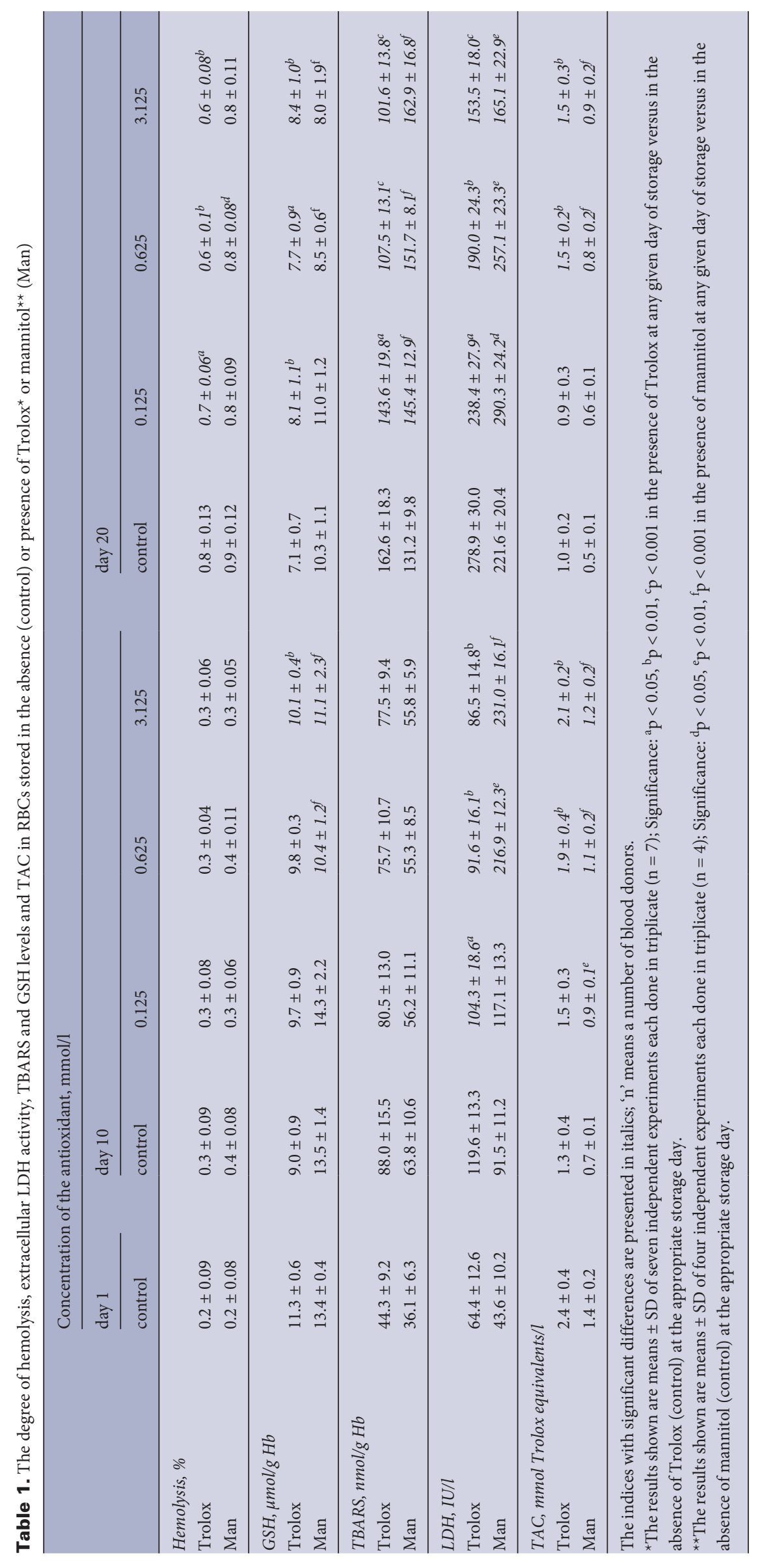




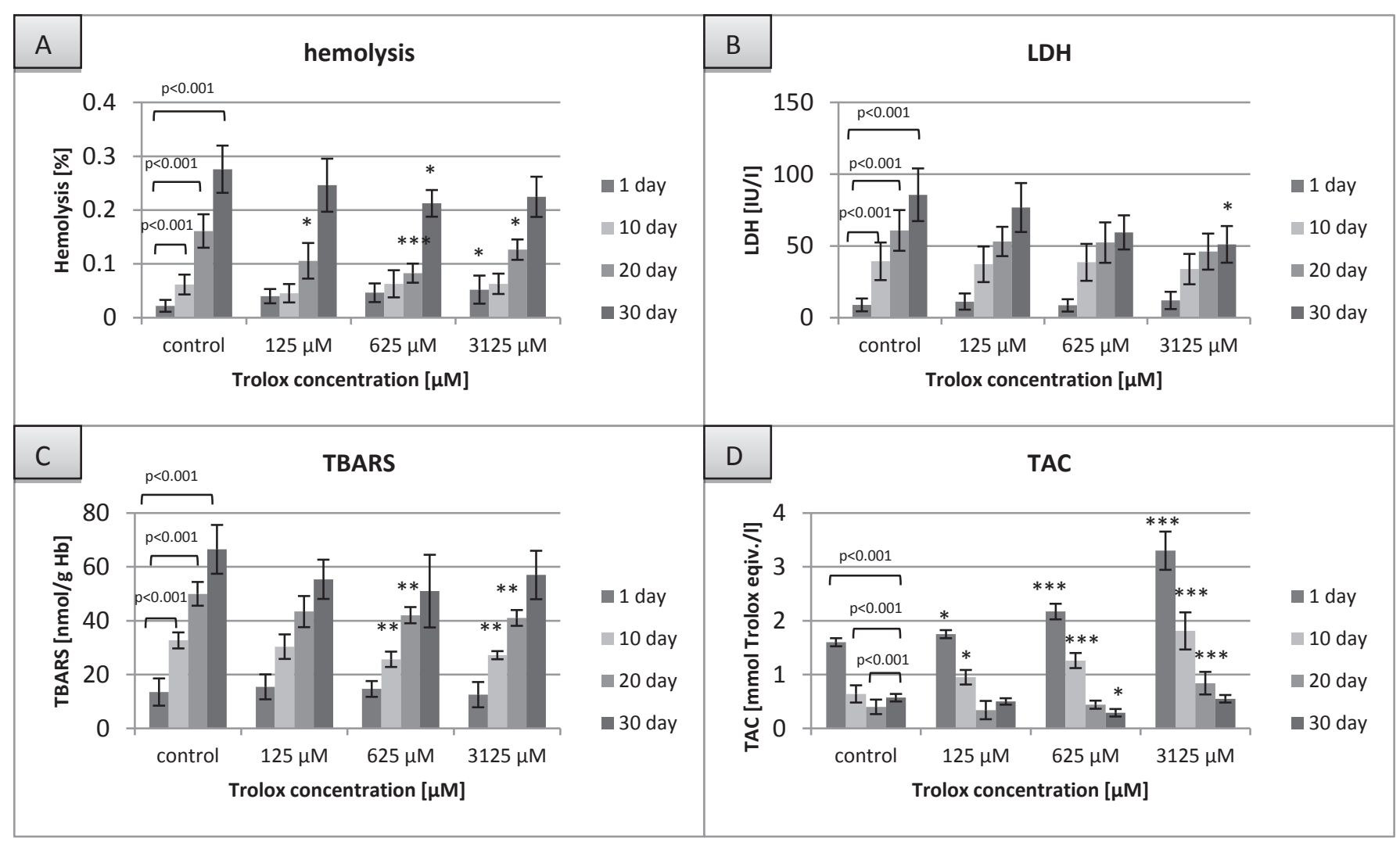

Fig. 1. The degree of hemolysis (A), extracellular LDH activity (B), TBARS concentration $(\mathbf{C})$ and TAC in the supernatant (D) of the RBCs stored in SAGM (control) or in SAGM supplemented with different Trolox concentrations. The results shown are means \pm SD of three independent experiments $(n=3)$, $n=a$ number of RBC transfusion units; ${ }^{*} \mathrm{p}<0.05,{ }^{* *} \mathrm{p}<0.01,{ }^{* * *} \mathrm{p}<0.001$ in the presence of Trolox at any given day of storage vs. in the absence of Trolox at the appropriate day of storage.

\section{Statistical Analysis}

The significance of differences between the mean values of various parameters was analyzed by one-way analysis of variance (ANOVA) followed by Dunnet's and Tukey's post hoc tests using 'Statistica' v.6.0 (StatSoft Inc., Tulsa, OK, USA). The significance of differences between the mean values of irradiated versus the appropriate non-irradiated samples was analyzed by paired Student's t-test. A level $\mathrm{p}<0.05$ was accepted as statistically significant.

\section{Results}

\section{Hemolysis, LDH Leakage, and Oxidative Changes in Manually}

\section{Prepared RBCs}

CPD-preserved $\mathrm{RBCs}(\mathrm{Ht}=70 \%)$ were stored in the absence (control) and presence of Trolox (at a concentration range of 0.001-3.125 mmol/l) or mannitol (0.125-3.125 mmol/l). Low doses of Trolox $(1,5$, and $25 \mu \mathrm{mol} / \mathrm{l})$ did not offer any protection (data not shown). Variables for RBCs stored in plastic tubes are presented in table 1.

Hemolysis significantly increased with time $(\mathrm{p}<0.01$ and $\mathrm{p}<$ 0.001 at day 10 and 20, respectively). Trolox supplementation in concentrations of 0.125 and $3.125 \mathrm{mmol} / \mathrm{l}$ significantly decreased hemolysis in RBCs at day 20 by $12.5 \%(\mathrm{p}<0.05)$ and $25 \%$, p < 0.01 ), respectively. RBCs long stored with mannitol had by about $15 \%$ lower hemolysis $(\mathrm{p}<0.05)$ rate compared to those stored without mannitol; the decrease was not concentration-dependent.
During the RBC storage a time-dependent raise of extracellular LDH occurred. Trolox supplementation, particularly at high concentrations $(0.625$ or $3.125 \mathrm{mmol} / \mathrm{l})$ significantly inhibited LDH leakage by 23 or $28 \%$ (both $\mathrm{p}<0.01)$ at day 10 and by $32(\mathrm{p}<0.01)$ or $45 \%(\mathrm{p}<0.001)$ at day 20 when compared to the appropriate controls. With mannitol, a reduced LDH leakage from RBCs (day 20) has been accomplished only at a concentration of $3.125 \mathrm{mmol} / \mathrm{l}$ mannitol ( $\mathrm{p}<0.01$ ); lower concentrations enhanced LDH leakage compared to control.

Supplementation with Trolox in high concentrations resulted in a significant inhibition of TBARS generation in RBCs by approximately $40 \%(\mathrm{p}<0.001)$ at day 20 . RBCs stored in the presence of Trolox maintained higher GSH levels compared to RBCs not containing the antioxidant. It could be shown that, compared to Trolox groups, there was less protection and increased TBARS formation (at day 20) in RBCs stored in the presence of mannitol.

A TAC assay measures the electron- or hydrogen-donating (scavenging) abilities of the sum of antioxidants in RBC-suspending medium (supernatant). There was a storage time-dependent decrease of the TAC due to oxidation of endogenous antioxidants, whereas Trolox had the ability to restore and, at high doses, to increase the TAC. At day 1, TAC of the RBC supernatant containing Trolox at a concentration of $3.125 \mathrm{mmol} / \mathrm{l}$ was approximately twofold higher ( $p<0.001)$ compared to the control without added Trolox (data not shown). Moreover, high amounts of Trolox kept 


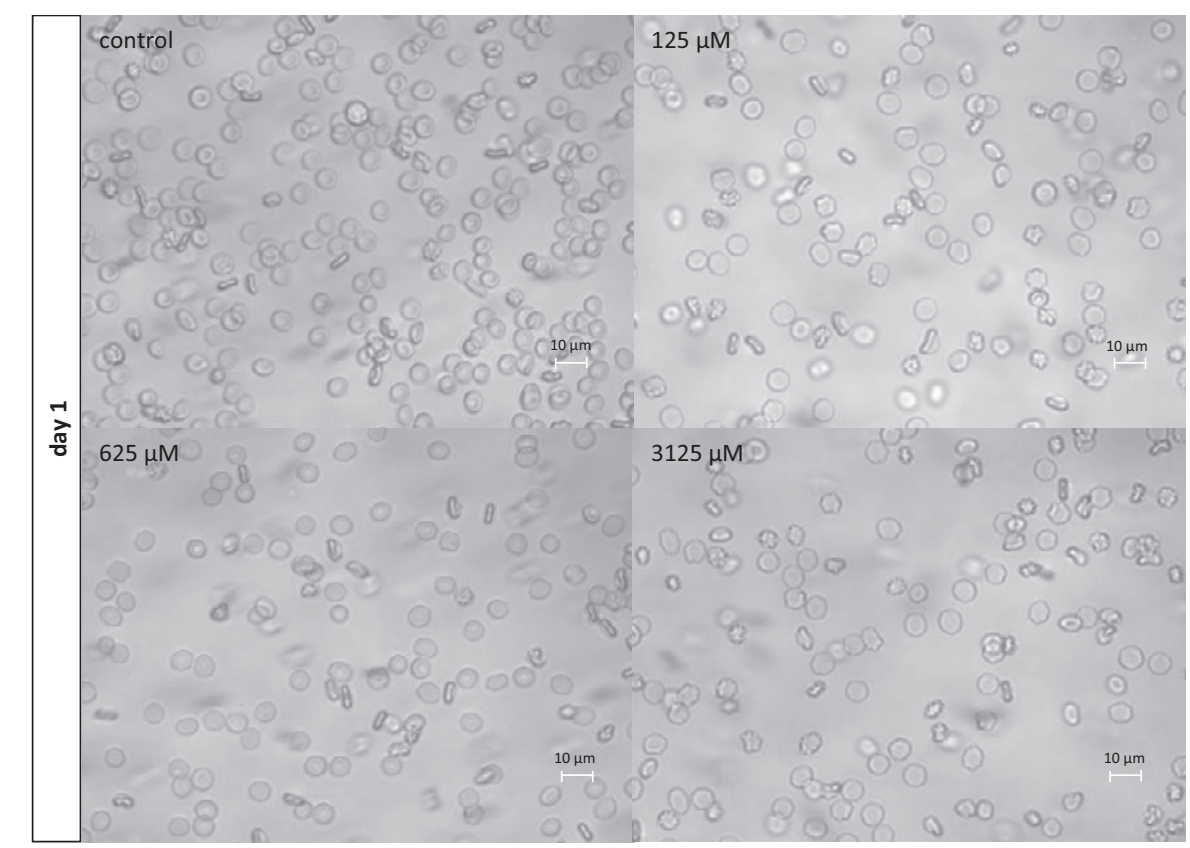

Fig. 2. Images of SAGM-preserved RBCs stored in the presence of Trolox $(125,625$ and 3,125 $\mu \mathrm{mol} / \mathrm{l})$ and in the absence of the antioxidant (control). Images were taken at day 1 and day 42 . Magnification of 630x (inverted microscope (Axio Observer; Zeiss, Jena, Germany) equipped with digital camera and software for digital image processing) The percentages of shape-changed cells were evaluated by counting approximately $350 \mathrm{RBCs}$ in randomly chosen fields.

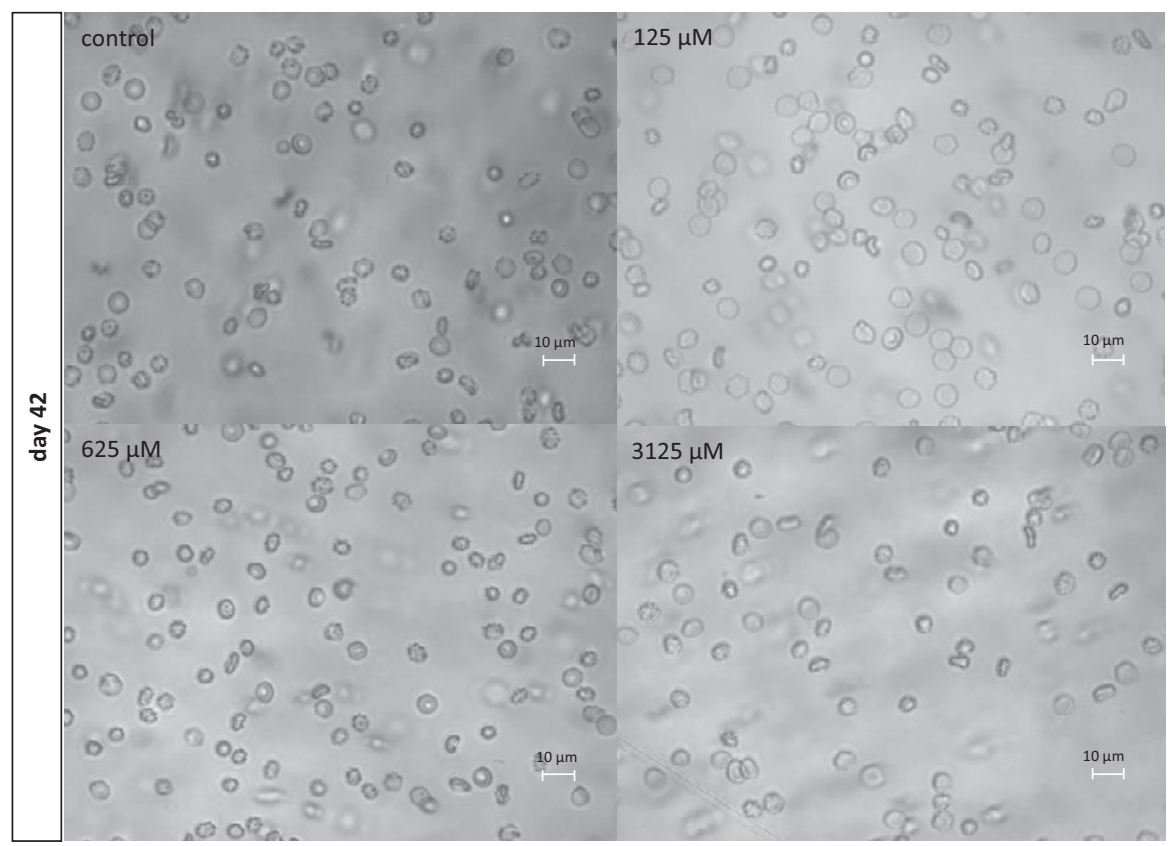

the TAC elevated in RBC medium over storage; at day 20, TAC was by about $50 \%(\mathrm{p}<0.01)$ higher in RBC units supplemented with $3.125 \mathrm{mmol} / \mathrm{l}$ Trolox when compared with controls from the same storage day. Mannitol supplementation in stored RBCs increased TAC of the supernatant in a concentration-dependent manner when compared with appropriate controls (not containing the antioxidant), and its efficacy was comparable to that of Trolox.

\section{Hemolysis, LDH Leakage, and Oxidative Changes in SAGM-}

Preserved RBCs

The commercially prepared 'pediatric' RBC units were stored in the absence (control) and presence of Trolox (at concentrations of 0.125-3.125 mmol/l). As expected, the selected custom RBC varia- bles were found to be proportionally lower in SAGM-preserved RBCs stored in blood bags compared to our experimental conditions (fig. 1). This was all the more reasonable since the actual $\mathrm{Ht}$ and WBC count are of major importance for the development of the storage lesion. The Ht levels were comparable in the groups of RBCs studied, whereas the WBC count was three orders of magnitude lower in the SAGM-preserved RBCs that had been filtered before storage. Nevertheless, the relative storage time-dependent changes were comparable in both experimental systems.

RBCs stored in SAGM supplemented with Trolox (0.625-3.125 $\mathrm{mmol} / \mathrm{l}$ ) had significantly lower hemolysis rate (by 30 at day 20 and $23 \%$ at day $30, \mathrm{p}<0.05$ ), $\mathrm{LDH}$ leakage (by $40 \%$ at day 30 ), and TBARS level (by approximately $20 \%$ over storage) as well as higher 
Fig. 3. Morphological changes of the RBCs stored in SAGM (control) or in SAGM supplemented with different Trolox concentrations. Magnification of $630 \times$ (inverted microscope Axio Observer. The percentages of shape-changed cells were evaluated by counting approximately 350 red cells in randomly chosen fields $(\mathrm{n}=3),{ }^{*} \mathrm{p}<0.05$ in the presence of Trolox at any given day of storage vs. in the absence of Trolox at the appropriate day of storage.

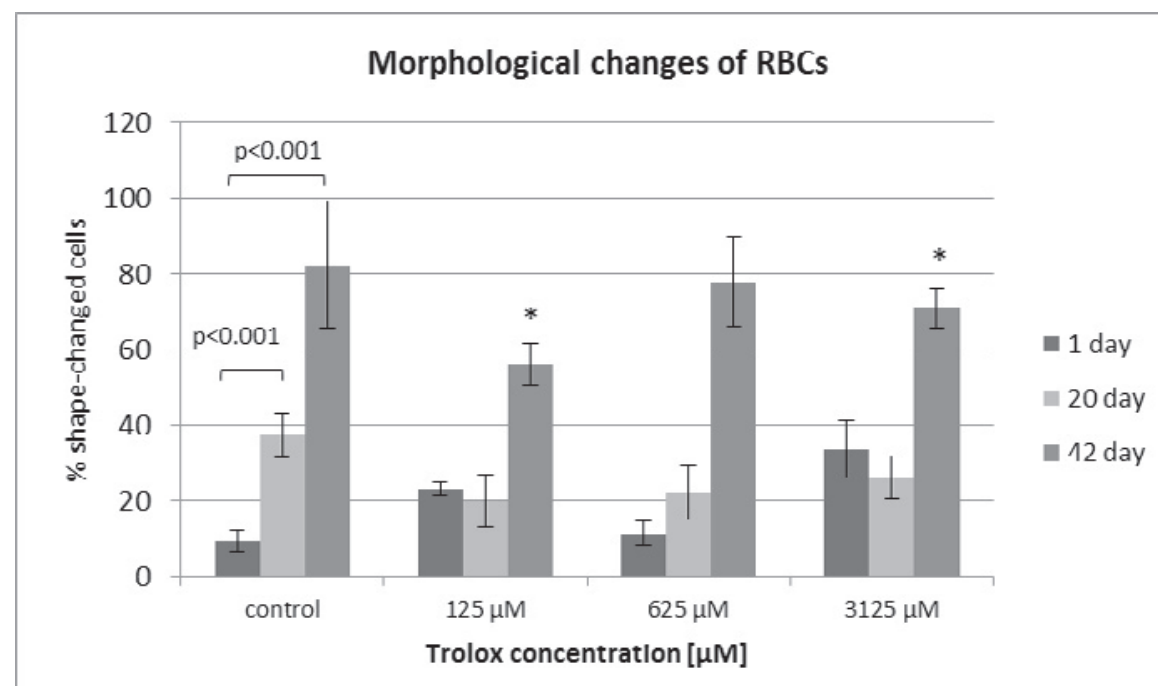

TAC (up to day 20), compared to the control (SAGM alone) at the corresponding day of storage. To address the structural concerns, morphological changes were evaluated in RBCs on days 1, 20, and 42 (fig. 2) using inverted microscopy (Axio Observer; Zeiss, Jena, Germany). By day 42 of hypothermic storage, approximately $80 \%$ of SAGM-RBCs displayed non-discoid shape, whereas the SAGMTrolox RBC storage resulted in a significantly lower $(\mathrm{p}<0.05)$ percentage of shape-changed RBCs (fig. 3).

\section{Discussion}

The rationale for using mannitol versus Trolox was that the former is a constituent of almost all RBC AS. While the significance of mannitol as a RBC membrane stabilizer has generally been accepted, its role in protection against storage-induced oxidative stress remains mostly unknown. We aimed to compare directly the protective abilities of Trolox and mannitol. Therefore, identical concentrations of both antioxidants were applied. Hemolysis, and the protection by antioxidants was more evident at day 20 which is consistent with findings reported by others [30,31]. At concentrations up to $3.125 \mathrm{mmol} / \mathrm{l}$, Trolox was somewhat more effective than mannitol in protecting against progressive hemolysis. However, the percentage of post-storage hemolysis might strongly depend on mannitol supplementation [16]. Importantly, concentrations of mannitol in commercial AS are over 10-fold higher than those used in our experiments. Mannitol can reduce hemolysis by balancing the osmotic effect of non-permeant intracellular solutes such as Hb, ATP, and 2,3-DPG [32] while Trolox might suppress oxidative stress-induced hemolysis even more effectively than mannitol. Trolox ( $4 \mathrm{mmol} / \mathrm{l})$ was reported to inhibit hemolysis of photo-treated (dimethylmethylene blue/red light) RBCs during the 4-week refrigerated storage [24], and Trolox $(2-10 \mu \mathrm{mol} / \mathrm{l})$ inhibited hemolysis (by up to 85\%) in lead-exposed RBCs [33].

$\mathrm{RBC}$ storage results in the formation of several $\mathrm{RBC}$ breakdown products that accumulate in the $\mathrm{RBC}$ unit which is accompanied by an increase of the free $\mathrm{Hb}$ concentration [34]. $\mathrm{Hb}$ autooxidation to produce superoxide anion $\left(\mathrm{O}^{-}\right)$has been recognized to be a significant source of reactive oxygen species (ROS) in RBC units [35]. Dismutation of $\mathrm{O}^{-}$generates hydrogen peroxide which in turn in the presence of transition metals can produce a hydroxyl radical via the Fenton reaction. Iron is released from $\mathrm{Hb}$ in a non-protein bound form ('free' iron) when RBCs are exposed to oxidative stress and/or during RBC aging [36]. The leakage of LDH to RBC medium can occur through direct membrane disruption (RBC lysis with concomitant release of $\mathrm{LDH}$ and $\mathrm{Hb}$ ). An excessive LDH release at the end of the storage period could also be associated with depletion of intracellular energy-rich nucleosides (ATP, ADP, ITP (inositol triphosphate)) [37]. The enhanced energy loss that arises at the 2- to 4-week storage can lead to insufficient phosphorylation of membrane proteins and a mismatch of membrane skeleton assembly resulting in a serious reduction of the membrane's mechanical stability and in an increased permeability.

Our results demonstrated that Trolox, in a dose-dependent manner, inhibited storage-induced leakage of LDH. Moreover, it protected against lipid peroxidation and, to a less extent, GSH depletion. In contrast, mannitol supplementation to the RBC medium protected cells from progressive LDH leakage during longterm-storage only at the highest concentration. Furthermore, preirradiation of RBCs containing mannitol significantly increased membrane permeability as reflected by LDH release after longer storage (data not shown). These findings are in agreement with the results of Hirayama et al. [21] who showed that the leakage of potassium from stored RBCs (also pre-irradiated at $30 \mathrm{~Gy}$ ) was promoted by mannitol due to increased osmotic pressure. Mannitol is believed to reduce hemolysis and protect membrane loss in RBC transfusion units [18]; it can induce changes of the membrane structure but the exact mechanisms of protection remain unknown. Mannitol has been identified a classical scavenger of hydroxyl radicals in various systems $[19,20]$. Studies by Regoli et al. [38] on the capacities of antioxidants to scavenge different radicals demonstrated that mannitol had a much higher scavenging ability 


\begin{tabular}{|c|c|c|c|c|}
\hline $\begin{array}{l}\text { Concentration of Trolox } \\
\text { in the } \mathrm{RBC} \text { unit, } \mathrm{mmol} / \mathrm{l}\end{array}$ & $\begin{array}{l}\text { Trolox, } \\
\text { g/RBC unit* }\end{array}$ & $\begin{array}{l}\text { Trolox, } \\
\text { g / } 10 \text { RBC units }\end{array}$ & $\begin{array}{l}\text { UL of any of } \alpha \text {-tocopherol } \\
\text { form in adults }\end{array}$ & $\begin{array}{l}\text { UL of any of a-tocopherol form } \\
\text { in subjects with various diseases }\end{array}$ \\
\hline 0.125 & 0.008 & 0.08 & \multirow{2}{*}{ 1,600 IU/day; 1 g/day } & \multirow[t]{2}{*}{ 400-3,200 IU/day; $0.25-2 \mathrm{~g} /$ day } \\
\hline 0.625 & 0.041 & 0.41 & & \\
\hline 3.125 & 0.203 & 2.03 & questionable & questionable \\
\hline
\end{tabular}

towards hydroxyl radicals, generated by the iron/ascorbate-driven Fenton reaction, than towards peroxyl radicals or peroxynitrite. Trolox has been reported to efficiently scavenge a wide variety of free radicals, including the hydroxyl radical and bioradical products arising from $\mathrm{OH}$ radical interactions [39, 40]. Similar to a-tocopherol, Trolox is primarily a chain-breaking antioxidant. Not surprisingly, in our study storage-induced lipid peroxidation was suppressed by Trolox, but not by mannitol, which remained in agreement with the results of a similar study on the effects of these antioxidants on lead-induced lipid peroxidation in RBCs [33]. The antioxidant potency of Trolox is related not only to its structural characteristics but also to its ability to interact with and to penetrate the lipid bilayers [41]. Due to its hydrophobic nature a-tocopherol distributes totally in the membrane. Thus it can stabilize biological membranes by restricting the mobility of their components. Trolox lacks the long fatty acid chain, but has the same chroman ring structure, and the reduction potentials of Trolox and $\alpha$-tocopherol determined by pulse radiolysis in aqueous solutions were found to be comparable. Trolox is assumed to function as an antioxidant by virtue of its ability to donate hydrogen from the hydroxyl group to the peroxyl radical (ROO ') converting it into a lipid hydroperoxide and a Trolox phenoxyl radical (or quinone radical) thus terminating the chain reaction [41, 42]. However, at physiological $\mathrm{pH}$, due to its carboxylic group, Trolox resides mainly in the aqueous phase and only partly in the lipid surface of phospholipid membrane system. For this reason, Trolox is favorable to scavenge free radicals generated in aqueous phase but is rather hindered to scavenge radicals generated inside the lipid phase. Studies by Alberto et al. [43] have shown Trolox to be a powerful hydroxyl and alkoxyl radical scavenger both in aqueous and lipid environments. It was also found to be a very good peroxyl radical scavenger in aqueous solution, while its protective effects against this particular kind of free radicals were only moderate in lipid solutions. The findings of the present study suggest that, apart from its strong antioxidant activity, Trolox could possibly decrease RBC membrane permeability through mechanistic interactions with the membrane. Depletion of GSH, due to the leakage to the medium and to some extent its oxidation to GSSG (oxidized glutathione), renders them more susceptible to oxidative stress. Trolox might prevent GSH oxidation and/or leakage; however, this effect was not so obvious, and the small protection effect offered by Trolox was not concentration-dependent. It has to be underlined that the results found in CPD-preserved RBCs are not of clinical relevance. Due to the limited availability of blood products, CPD- preserved RBCs were included into the study to better understand the protective potential of the two antioxidants separately.

The commercial RBC units stored in SAGM-Trolox had significantly lower hemolysis, LDH leakage, and lipid peroxidation level compared to the RBCs stored in SAGM alone, suggesting better maintenance of the erythrocyte membrane properties. Hemolysis rate and TBARS levels did not differ significantly between RBCs stored with 0.625 or $3.125 \mathrm{mmol} / \mathrm{l}$ Trolox raising the question which antioxidant concentration should be used to provide optimal RBC protection. This issue has to be addressed in further studies including other variables important for RBC quality assessment. Although a significant TAC increase of the RBC supernatant supplemented with Trolox was evident at the first 2-3 weeks of storage, it is not known thus far how this contributes to oxidative stress reduction over the whole storage period. The microscopy analysis confirmed that SAGM-preserved RBC storage in the presence of Trolox did not have deleterious effects on RBC morphology. Morphological changes typical for the long-term hypothermic storage reported by others [31] with even smaller percentage of non-discoid RBC have been noticed.

Compared to other fat-soluble vitamins, the toxicity of vitamin $\mathrm{E}$ is rather low. The recommended dietary allowance of vitamin $\mathrm{E}$ has been established as $15 \mathrm{mg} /$ day and listed the tolerable upper intake level of any $\boldsymbol{\alpha}$-tocopherol form as $1,000 \mathrm{mg} /$ day $(1,600$ IU/day) [44]. While in most healthy adults short-term supplementation with up to 1,600 IU of vitamin E appears to be well tolerated and have minimal side effects, it may be too high for the long-term use, especially in patients with chronic diseases. On the other hand, many meta-analyses that combined the results of several randomized controlled trials of vitamin E supplementation for various diseases, including heart disease, end-stage renal failure and Alzheimer's disease, showed no major adverse effects associated with intakes of up to $3200 \mathrm{IU} /$ day vitamin E [44]. Due to the existing mechanisms to routinely eliminate potential excess levels of vitamin E, even high intakes do not cause its accumulation in the liver or other tissues [45]. Therefore, it can be proposed that transfusion of 10 units of the RBCs supplemented with a vitamin E analogue, at a final concentration of $625 \mu \mathrm{mol} / \mathrm{l}$, should be relatively safe (table 2). However, this issue especially regarding massive transfusions ( $\geq 10$ units / $24 \mathrm{~h}$ ) must be kept in mind. In conclusion, the comparison of two antioxidants in the present study showed that Trolox appeared to be superior to mannitol in providing RBC protection against the oxidative stress-mediated damage. Both antioxidants had a comparable potential to increase TAC of the RBC me- 
dium, but the protective mechanisms by which they exert their action are different. Trolox was compatible with SAGM solution which make it a good candidate to be further studied as an additional component of the currently used AS. The present study provides strong evidence of the beneficial effects of supplementing RBC storage solutions with membrane-interacting antioxidants, such as vitamin $\mathrm{E}$ analogues.

\section{Acknowledgments}

This study was supported by grant 506/1136 and grant 545/759 from the University of Lodz.

\section{Disclosure Statement}

The authors declare that there is no conflict of interest associated with this manuscript.

\section{References}

1 Zimmermann R, Wintzheimer S, Weisbach V, Strobel J, Zingsem J, Eckstein R: Influence of prestorage leukoreduction and subsequent irradiation on in vitro red blood cell (RBC) storage variables of RBCs in additive solution saline-adenine-glucose-mannitol. Transfusion 2009; 49:75-80.

$\checkmark 2$ Hess JR: Red cell changes during storage. Transfus Apher Sci 2010;43:51-59.

3 Sparrow RL: Time to revisit red blood cell additive solutions and storage conditions: A role for 'omics' analyses. Blood Transfus 2012;10(suppl 2):s7-11.

4 Klein HG, Spahn DR, Carson JL: Red blood cell transfusion in clinical practice. Lancet 2007;370:415-426.

5 Reverberi R, Govoni M, Verenini M: Deformability and viability of irradiated red cells. Ann Ist Super Sanita 2007;43:176-185.

6 Hod EA, Zhang N, Sokol SA, Wojczyk BS, Francis RO, Ansaldi D, Francis KP, Della-Latta P, Whittier S, Sheth S, Hendrickson JE, Zimring JC, Brittenham GM, Spitalnik SL: Transfusion of red blood cells after prolonged storage produces harmful effects that are mediated by iron and inflammation. Blood 2010;115:4284-4292.

7 Kim-Shapiro DB, Lee J, Gladwin MT: Storage lesion: role of red blood cell breakdown. Transfusion 2011;51: 844-851.

8 Roback JD: Vascular effects of the red blood cell storage lesion. Hematology Am Soc Hematol Educ Program 2011;2011:475-479.

9 Yazdanbakhsh K, Bao W, Zhong H: Immunoregulatory effects of stored red blood cells. Hematology Am Soc Hematol Educ Program 2011;2011:466-469.

10 Pavenski K, Saidenberg E, Lavoie M, Tokessy M, Branch DR: Red blood cell storage lesions and related transfusion issues: a Canadian Blood Services research and development symposium. Transfus Med Rev 2012; 26:68-84.

11 Koch CG, Figueroa PI, Li L, Sabik JF, 3rd, Mihaljevic T, Blackstone EH: Red blood cell storage: how long is too long? Ann Thorac Surg 2013;96:1894-1899.

12 Flegel WA, Natanson C, Klein HG: Does prolonged storage of red blood cells cause harm? Br J Haematol 2014;165:3-16.

13 Dumaswala UJ, Zhuo L, Jacobsen DW, Jain SK, Sukalski KA: Protein and lipid oxidation of banked human erythrocytes: role of glutathione. Free Radic Biol Med 1999;27:1041-1049.

14 Zbikowska HM, Antosik A: Irradiation dose-dependent oxidative changes in red blood cells for transfusion. Int J Radiat Biol 2012;88:654-660.

15 Kim YK, Kwon EH, Kim DH, Won DI, Shin S, Suh JS: Susceptibility of oxidative stress on red blood cells exposed to gamma rays: hemorheological evaluation. Clin Hemorheol Microcirc 2008;40:315-324.

16 Hess JR, Sparrow RL, van der Meer PF, Acker JP, Cardigan RA, Devine DV: Red blood cell hemolysis during blood bank storage: using national quality management data to answer basic scientific questions. Transfusion 2009;49:2599-2603.
17 Zbikowska HM, Antosik A, Szejk M, Bijak M, Nowak P: A moderate protective effect of quercetin against gamma-irradiation- and storage-induced oxidative damage in red blood cells for transfusion. Int J Radiat Biol 2014;90:1201-1210.

18 Hess JR: An update on solutions for red cell storage. Vox Sang 2006;91:13-19.

19 Shen B, Jensen RG, Bohnert HJ: Mannitol protects against oxidation by hydroxyl radicals. Plant Physiol 1997;115:527-532.

20 Bhattacharyya J, Datta AG: Studies on the effects of lipopolysaccharide on lipid peroxidation of erythrocyte and its reversal by mannitol and glycerol. J Physiol Pharmacol 2001;52:145-152.

21 Hirayama J, Abe H, Azuma H, Ikeda H: Leakage of potassium from red blood cells following gamma ray irradiation in the presence of dipyridamole, Trolox, human plasma or mannitol. Biol Pharm Bull 2005;28: 1318-1320.

22 Wu TW, Hashimoto N, Wu J, Carey D, Li RK, Mickle DA, Weisel RD: The cytoprotective effect of Trolox demonstrated with three types of human cells. Biochem Cell Biol 1990;68:1189-1194.

23 Guo C, He Z, Wen L, Zhu L, Lu Y, Deng S, Yang Y, Wei Q, Yuan H: Cytoprotective effect of Trolox against oxidative damage and apoptosis in the NRKk-52E cells induced by melamine. Cell Biol Int 2012;36:183-188.

24 Besselink GA, van Engelenburg FA, Ebbing IG, Hilarius PM, de Korte D, Verhoeven AJ: Additive effects of dipyridamole and Trolox in protecting human red cells during photodynamic treatment. Vox Sang 2003;85:25-30.

25 Ben-Hur E, Rywkin S, Rosenthal I, Geacintov NE, Horowitz B: Virus inactivation in red cell concentrates by photosensitization with phthalocyanines: protection of red cells but not of vesicular stomatitis virus with a water-soluble analogue of vitamin E. Transfusion 1995;35:401-406.

26 Janatpour K, Denning L, Nelson K, Betlach B, Mackenzie M, Holland P: Comparison of X-ray vs. gamma irradiation of CPDA-1 red cells. Vox Sang 2005;89:215-219.

27 Wroblewski F, Ladue JS: Lactic dehydrogenase activity in blood. Proc Soc Exp Biol Med 1955;90:210-213.

28 Stocks J, Dormandy TL: The autoxidation of human red cell lipids induced by hydrogen peroxide. Br J Haematol 1971;20:95-111.

29 Erel O: A novel automated direct measurement method for total antioxidant capacity using a new generation, more stable ABTS radical cation. Clin Biochem 2004;37:277-285.

30 Goes EG, Ottoboni MA, Palma PV, Morais FR, Pela CA, Borges JC, Covas DT: Quality control of blood irradiation with a teletherapy unit: damage to stored red blood cells after cobalt-60 gamma irradiation. Transfusion 2008;48:332-340.

31 Ran Q, Hao P, Xiao Y, Zhao J, Ye X, Li Z: Effect of irradiation and/or leucocyte filtration on $\mathrm{RBC}$ storage lesions. PLoS One 2011;6:e18328.
32 Jarvis HG, Gore DM, Briggs C, Chetty MC, Stewart GW: Cold storage of 'cryohydrocytosis' red cells: the osmotic susceptibility of the cold-stored erythrocyte. Br J Haematol 2003;122:859-868.

33 Casado MF, Cecchini AL, Simao AN, Oliveira RD, Cecchini R: Free radical-mediated pre-hemolytic injury in human red blood cells subjected to lead acetate as evaluated by chemiluminescence. Food Chem Toxicol 2007;45:945-952.

34 Bosman GJ, Werre JM, Willekens FL, Novotny VM: Erythrocyte ageing in vivo and in vitro: structural aspects and implications for transfusion. Transfus Med 2008;18:335-347.

35 Cimen MY: Free radical metabolism in human erythrocytes. Clin Chim Acta 2008;390:1-11.

36 Comporti M, Signorini C, Buonocore G, Ciccoli L: Iron release, oxidative stress and erythrocyte ageing. Free Radic Biol Med 2002;32:568-576.

37 Leitner GC, Neuhauser M, Weigel G, Kurze S, Fischer $\mathrm{MB}$, Hocker P: Altered intracellular purine nucleotides in gamma-irradiated red blood cell concentrates. Vox Sang 2001;81:113-118.

38 Regoli F, Winston GW: Quantification of total oxidant scavenging capacity of antioxidants for peroxynitrite, peroxyl radicals, and hydroxyl radicals. Toxicol Appl Pharmacol 1999;156:96-105.

39 Aruoma OI, Evans PJ, Kaur H, Sutcliffe L, Halliwell B: An evaluation of the antioxidant and potential pro-oxidant properties of food additives and of trolox C, vitamin E and probucol. Free Radic Res Commun 1990;10: 143-157.

40 Stefek M, Kyselova Z, Rackova L, Krizanova L: Oxidative modification of rat eye lens proteins by peroxyl radicals in vitro: protection by the chain-breaking antioxidants stobadine and trolox. Biochim Biophys Acta 2005; 1741:183-190.

41 Lucio M, Nunes C, Gaspar D, Ferreira H, Lima JLFC, Reis S: Antioxidant activity of vitamin $\mathrm{E}$ and trolox: understanding of the factors that govern lipid peroxidation studies in vitro. Food Biophysics 2009;4:312-320

42 Rezk BM, Haenen GR, Van Der Vijgh WJ, Bast A: The extraordinary antioxidant activity of vitamin E phosphate. Biochim Biophys Acta 2004;1683:16-21.

43 Alberto ME, Russo N, Grand A, Galano A: A physicochemical examination of the free radical scavenging activity of Trolox: mechanism, kinetics and influence of the environment. Phys Chem Chem Phys 2013;15: 4642-4650.

44 Hathcock JN, Azzi A, Blumberg J, Bray T, Dickinson A, Frei B, Jialal I, Johnston CS, Kelly FJ, Kraemer K, Packer L, Parthasarathy S, Sies H, Traber MG: Vitamins $\mathrm{E}$ and $\mathrm{C}$ are safe across a broad range of intakes. Am J Clin Nutr 2005;81:736-745.

45 Traber MG: Mechanisms for the prevention of vitamin E excess. J Lipid Res 2013;54:2295-2306. 